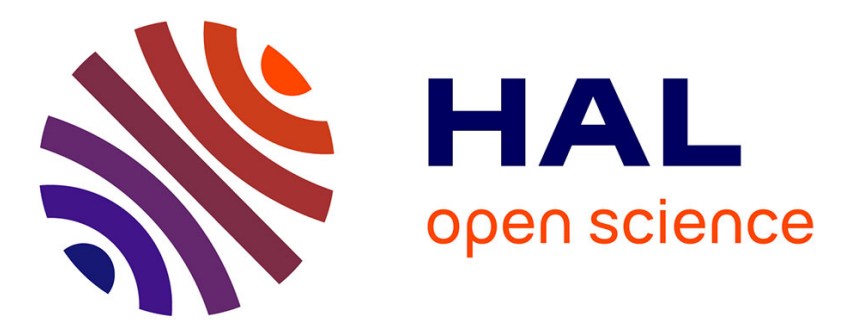

\title{
Ionic liquid-assisted morphosynthesis of gold nanorods using polyethyleneimine-capped seeds
}

Aniket Thete, Oscar Rojas, David Neumeyer, Joachim Koetz, Erik Dujardin

\section{To cite this version:}

Aniket Thete, Oscar Rojas, David Neumeyer, Joachim Koetz, Erik Dujardin. Ionic liquid-assisted morphosynthesis of gold nanorods using polyethyleneimine-capped seeds. RSC Advances, 2013, 3 (34), pp.14294-14298. 10.1039/c3ra22112a . hal-01798019

\section{HAL Id: hal-01798019 https://hal.science/hal-01798019}

Submitted on 20 Jun 2019

HAL is a multi-disciplinary open access archive for the deposit and dissemination of scientific research documents, whether they are published or not. The documents may come from teaching and research institutions in France or abroad, or from public or private research centers.
L'archive ouverte pluridisciplinaire HAL, est destinée au dépôt et à la diffusion de documents scientifiques de niveau recherche, publiés ou non, émanant des établissements d'enseignement et de recherche français ou étrangers, des laboratoires publics ou privés. 


\section{Mathematisch-Naturwissenschaftliche Fakultät}

Aniket Thete | Oscar Rojas | David Neumeyer | Joachim Koetz Erik Dujardin

\section{Ionic liquid-assisted morphosynthesis of gold nanorods using polyethyleneimine- capped seeds}

Suggested citation referring to the original publication:

RSC Advances 3 (2013), pp. 14294-14298

DOI http://dx.doi.org/10.1039/c3ra22112a

Postprint archived at the Institutional Repository of the Potsdam University in:

Postprints der Universität Potsdam

Mathematisch-Naturwissenschaftliche Reihe ; 245

ISSN 1866-8372

http://nbn-resolving.de/urn:nbn:de:kobv:517-opus4-95196 

Cite this: RSC Advances, 2013, 3, 14294

\section{lonic liquid-assisted morphosynthesis of gold nanorods using polyethyleneimine-capped seeds $\dagger$}

Received 11th September 2012,

Accepted 28th June 2013

Aniket Thete, ${ }^{a}$ Oscar Rojas, ${ }^{\text {b }}$ David Neumeyer, ${ }^{a}$ Joachim Koetz ${ }^{\mathrm{b}}$ and Erik Dujardin*a

DOI: $10.1039 / c 3 r a 22112 a$

www.rsc.org/advances

Seed-mediated gold nanorods with tunable lengths are prepared using new polyethyleneimine-capped gold nanoparticles synthesized in ionic liquid. The effect of polyethyleneimine and ionic liquid during nanorod growth is investigated and shows a marked effect on their final aspect ratio.

The versatile properties of metallic nanoparticles have been exploited in a wide range of fields from biology to catalysis and plasmonics. $^{1-4}$ In the past decade, the control of the particle morphology from isotropic to low dimensional structures such as nanorods, ${ }^{5-8}$ nanowires $^{9-11}$ or nanoplates ${ }^{12-14}$ has opened the way towards functional engineering of metal colloids. For example, nanoplasmonics has demonstrated optical information propagation beyond light diffraction limits in narrow, large aspect ratio (AR) and low dissipative waveguides such as single crystalline gold nanorods ( $\mathrm{Au} \mathrm{NR}$ ) over micrometer length. ${ }^{15-17}$ The synthetic challenge resides in the control of the metal structural quality and the tuning of the nanorods length and diameter. ${ }^{18}$ This controlled morphosynthesis of nanorods has so far been achieved by selecting capping agents with high affinity for specific crystallographic faces of the growing metal particle, ${ }^{19}$ the archetypal and almost exclusive examples being cetyltrimethylammonium bromide (CTAB) $)^{20,21}$ and poly( $N$-vinylpyrrolidone) (PVP). ${ }^{2,23}$ Recently ionic liquids (IL), a new class of organic salts with a melting temperature below $100{ }^{\circ} \mathrm{C}$, have been used as surface modifiers in the synthesis of mesoporous materials ${ }^{24}$ as well as metallic nanoparticles including gold. ${ }^{25,26}$ ILs are potential "green" solvents for organic and inorganic reactions with specific electrostatic and coordination effects that show improved stabilization for colloidal dispersion. ${ }^{27}$ ILs have so far been primarily used as solutes or pure solvents to promote the colloidal

${ }^{a}$ NanoSciences Group, CEMES CNRS UPR 8011, BP 94347, 29 r. J. Marvig, 31055 Toulouse Cedex 4, France.E-mail: dujardin@cemes.fr

${ }^{b}$ University of Potsdam, Institute of Chemistry, Karl-Liebknecht-Str. 24/25 D-14476 Potsdam, Germany

$\dagger$ Electronic supplementary information (ESI) available: Experimental details, UVvisible spectra of AU seeds and calculated spectra of Au NR, crystallinity study of AuNR, AuNR length histograms, DLS spectra, AFM study. See DOI: 10.1039/ c3ra22112a stability of pre-formed metal nanoparticles. ${ }^{28,29}$ Interestingly, when metal nanoparticles have been synthesized in IL solvents, a specific affinity of the IL for crystallographic facets has been observed and resulted in shape directing action. ${ }^{25,30-32}$ However, to the best of our knowledge, ILs in solution have never been used specifically as shape-directing agent during nanoparticle growth, like CTAB or PVP.

Here, we report the tuning of the aspect ratio of Au NR by using the adverse effects of 1-ethyl-3-methylimidazolium hexylsulfate $\left(\mathrm{emimHexSO}_{4}\right)$ ionic liquid and polyethyleneimine (PEI) on the nanorod growth. The Au NR growth is triggered in a standard CTAB-HAuCl ${ }_{4}$ aqueous growth solution (GS) with a new type of $\mathrm{Au}$ seeds produced in pure emimHexSO $\mathrm{S}_{4}$ and capped with PEI (Fig. 1). We show that the AR of the nanorods is increased by adjusting the emimHexSO $\mathrm{S}_{4}$ : PEI molar ratio. The PEI cationic polymer chain comprises a large number of secondary amine groups that bind strongly but non-specifically to Au surfaces. An increased amount of PEI results in the shortening and thickening

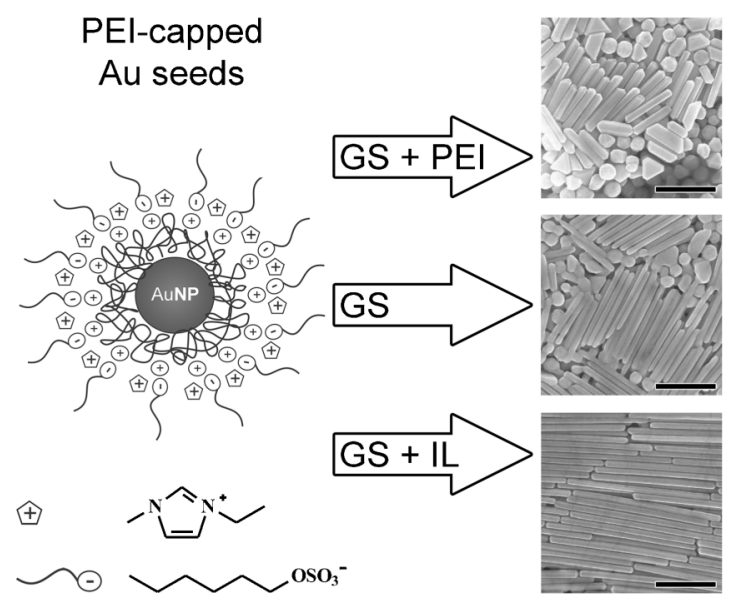

Fig. 1 Gold nanorods of AR varying between 5 (top) and 20 (bottom) are obtained from $5 \mathrm{~nm}$ PEl-capped Au seeds produced in pure emimHexSO $\mathrm{SL}_{4} \mathrm{~L}$ by changing the proportions of PEI and IL added to the aqueous CTAB-containing growth solution (GS). Scale bars are $500 \mathrm{~nm}$. 
of the $\mathrm{Au}$ NR. EmimHexSO 4 is a water-soluble ionic liquid comprising an imidazolium cation and an alkyl sulphate anion. The imidazolium is also an efficient gold-binding agent. ${ }^{27}$ However, the hexylsulfate anion interacts with the CTAB selfassembled monolayer (SAM $)^{33}$ and thus amplifies the growth inhibition of the $\{100\} \mathrm{Au}$ facets leading to thinner and longer $\mathrm{Au}$ NRs. ${ }^{6}$ The high efficiency of pure CTAB to promote $1 \mathrm{D}$ growth is also known to promote the inertness of the capping CTAB selfassembled multilayer to post-synthetic chemical treatment, which is generally limited to the nanorods tips. ${ }^{34,35}$ While postfunctionalization improves the bio-compatibility of $\mathrm{Au} \mathrm{NR},{ }^{36}$ no systematic approach for CTAB-coated NR has yet been discovered. The intimate co-action of emimHexSO 4 and CTAB could lead to a richer surface chemistry of $\mathrm{Au} \mathrm{NR}$. A further insight on the respective roles of PEI and emimHexSO $\mathrm{IL}_{4}$ at the surface of the gold nanoparticles is obtained by a systematic study of the hydrodynamic radius of the PEI-capped seeds in the presence of the emimHexSO $\mathrm{IL}_{4}$ in an aqueous solution containing CTAB and $\mathrm{HAuCl}_{4}$.

First, gold seeds are synthesized in pure emimHexSO $\mathrm{SI}_{4}$ IL. A 0.5 wt\% PEI solution and a $2 \mathrm{mM} \mathrm{HAuCl}_{4}$ solution are mixed in $1: 1$ weight ratio at room temperature and heated up to $100{ }^{\circ} \mathrm{C}$ for 20 min. The hydrothermal reduction of $\mathrm{Au}(\mathrm{III})$ by the secondary amines of PEI results in a dark red solution of small monodisperse $\mathrm{Au}$ nanoparticles. A size distribution of the nanoparticles characterized by transmission electron microscopy (TEM) is shown in Fig. 2. The average size is $4.6 \pm 1.2 \mathrm{~nm}$. UV-visible spectra of the freshly prepared nanoparticles show a surface plasmon absorption at $524 \mathrm{~nm}$ (Fig. 4, thin continuous line). The PEI-capped nanoparticles remain stable in suspension with no sign of aggregation after a shelf life exceeding two years. (See ESI, $\dagger$ Fig. S1). PEI, which provides a high density of cationic amine moieties, acts as a polydentate capping layer of the gold surface therefore accounting for the high stability of these small particles. Interestingly, when similar Au seeds are prepared in 1-ethyl-3methylimidazolium ethylsulfate $\left(\mathrm{emimEtSO}_{4}\right),{ }^{37}$ the seed stability is significantly reduced pointing to a complementary stabilizing effect of longer alkyl chain of the anions.

Since both emimHexSO $\mathrm{S}_{4}$ and PEI are hydrophilic, these particles can directly act as seeds for the aqueous synthesis of Au NR. Moreover, the gold-reducing activity of PEI and the goldcapping affinity of both PEI and IL as well as the potential
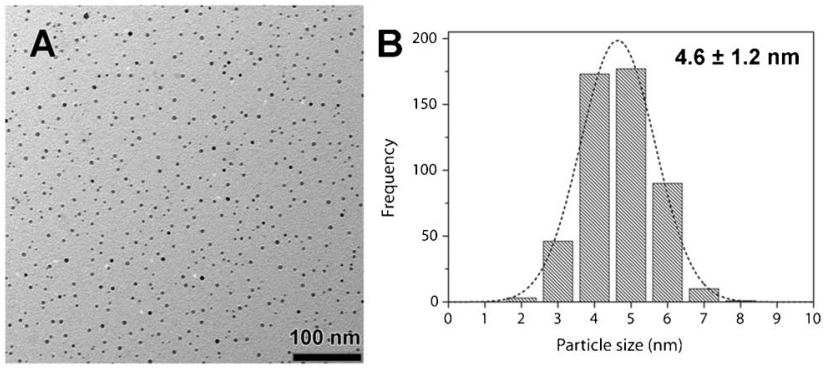

Fig. 2 (A) TEM micrograph of PEl-stabilized Au nanoparticles synthesized in emimHexSO4 ionic liquid. (B) Nanoparticle size distribution centered at $4.6 \pm 1.2$ $\mathrm{nm}$.
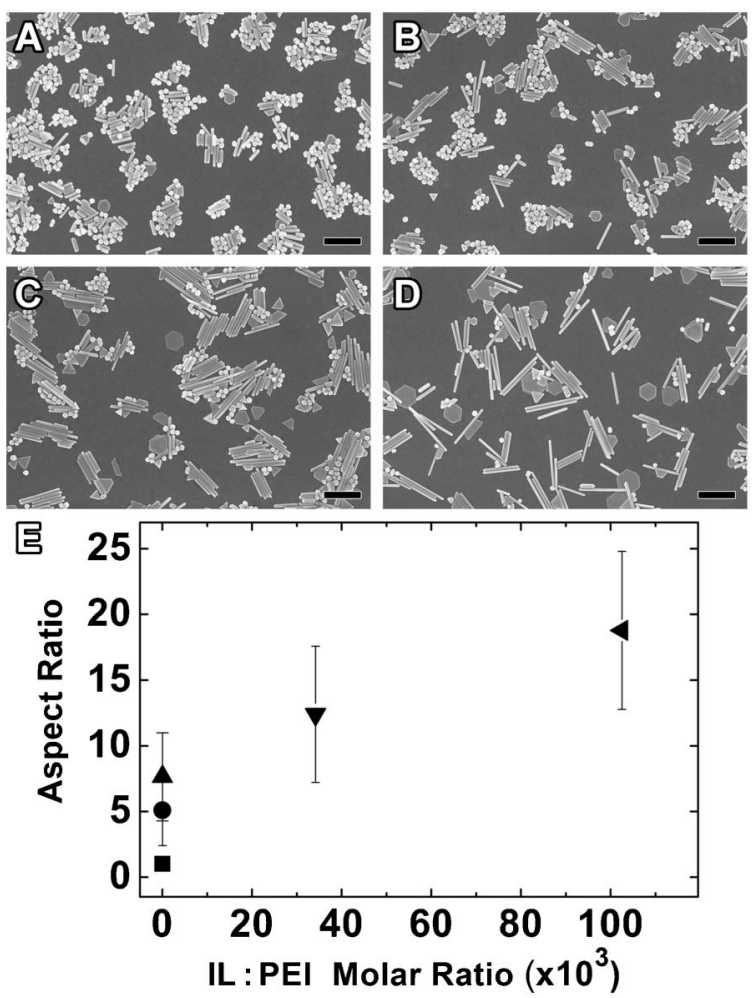

Fig. 3 (A-D) SEM micrographs of Au nanorods obtained from PEl-capped Au seeds in IL added to a standard CTAB-ascorbic acid aqueous growth solution with different final concentration of PEI and IL in the growth solution. $\mathrm{A}$. [IL] $=4.1 \mathrm{mM}$, $[\mathrm{PEI}]=615 \mu \mathrm{M}$. B. [IL] $=12.3 \mathrm{mM},[\mathrm{PEI}]=615 \mu \mathrm{M}$. C. [IL] $=4.1 \mathrm{mM},[\mathrm{PEI}]=0.12 \mu \mathrm{M}$. D. $[\mathrm{IL}]=12.3 \mathrm{mM},[\mathrm{PEI}]=0.12 \mu \mathrm{M}$. (E). Variation in the AR of the Au nanorods with the IL : PEl molar ratio for conditions A ( $), B(\boldsymbol{\Delta}), C(\boldsymbol{\nabla}), \mathrm{D}(\boldsymbol{4})$ and $(\boldsymbol{\square})[\mathrm{PEI}]=800 \mu \mathrm{M}$, $[\mathrm{IL}]=4.1 \mathrm{mM}$. (Scale bars $500 \mathrm{~nm}$.)

interaction of $\mathrm{HexSO}_{4}$ with CTAB suggest that these seeds, with or without added PEI or IL, could have a morphosynthetic activity and influence the Au NR aspect ratio. We have thus modified the single-step version of the conventional method of $\mathrm{Au}$ NR

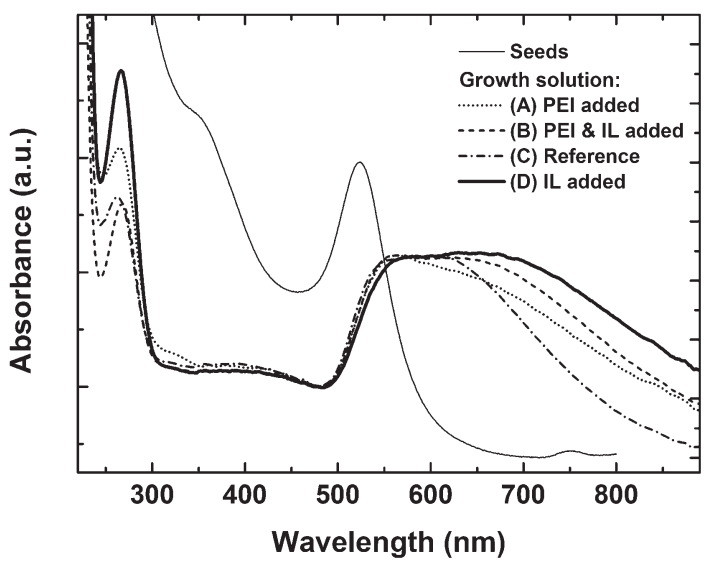

Fig. 4 UV-visible absorption spectra of PEl-stabilized Au seeds (thin continuous) and Au nanorods obtained in growth solutions A (dot), B (dash), C (dash dot), D (thick continuous). 
preparation described by Murphy et al. ${ }^{5}$ in order to obtain a stable mixture of IL and CTAB solutions. Typically, $5 \mu \mathrm{L}$ of PEI-capped seeds in IL are added to $5 \mathrm{~mL}$ of a growth solution containing 0.3 $\mathrm{mM} \mathrm{HAuCl}{ }_{4}, 0.2 \mathrm{mM}$ ascorbic acid, $0.1 \mathrm{M} \mathrm{CTAB}$ and $0.1 \mathrm{vol} \%$ concentrated $\mathrm{HNO}_{3}$. In this protocol, ascorbic acid and PEI are the gold-reducing agents, $\mathrm{PEI}, \mathrm{IL}, \mathrm{HNO}_{3}$ and $\mathrm{CTAB}$ have a known affinity for the metallic gold surface and thus act as growth inhibitors and capping agents. The reaction solution is kept undisturbed at $26{ }^{\circ} \mathrm{C}$ overnight to yield a light pink solution that is drop-cast onto substrates for electron microscopy characterization. Fig. 3C shows that long and monodisperse nanorods are produced with a $c a .15 \%$ particle yield. Close examination in electron microscopy of the nanorods sides and tips reveals their pentatwinned structure (Fig. S3, ESI $\dagger$ ), as already evidenced for the pure CTAB-driven protocol. ${ }^{6}$ The nanorod diameter and length are 50 $\pm 10 \mathrm{~nm}$ and 400-800 $\mathrm{nm}$ respectively, with an averaged AR of $12.5 \pm 3$ after a single step growth. Interestingly, in similar growth conditions but with citrate-or CTAB-stabilized seeds, ${ }^{11}$ the AR is, at most, 5 after a single step growth and the complete three-step protocol is required to reach AR of 15-20. Since the IL and PEI introduced alongside the seeds, at the respective final concentrations of $0.12 \mu \mathrm{M}$ and $4.1 \mathrm{mM}$ (reference, growth medium $\mathrm{C}$ ), have a marked influence on the nanorod morphology, we have investigated the evolution of this morphology upon varying the $\mathrm{IL}$ and PEI contents and relative molar ratio in the growth solution. When both extra PEI and IL are added at the final concentrations of $615 \mu \mathrm{M}$ and $12.3 \mathrm{mM}$ (growth medium $\mathrm{B}$ ), the nanorods AR is significantly reduced to $7.6 \pm 3$ (Fig. 3B). The main effect is not only the reduction of the average length of the nanorods to less than $450 \pm 50 \mathrm{~nm}$ but also a $40 \%$ increase of the diameter to $68 \pm 13 \mathrm{~nm}$. Interestingly the addition of extra PEI alone to the reference condition $\mathrm{C}$ (growth medium $\mathrm{A}$ ) leads to the same increased diameter $(67 \pm 13 \mathrm{~nm})$ but further reduces the nanorods length which is limited to $250 \pm 50 \mathrm{~nm}$ (Fig. 3A) with a very large yield of isotropic nanoparticles. On the contrary, the sole addition of extra IL (growth medium D) results in a substantial increase of the nanorods length to an average value $1.0 \mu \mathrm{m}$ with a preserved narrow diameter $(48 \pm 9 \mathrm{~nm})$ and a noticeably improved yield of $20 \%$ (Fig. 3D).

The variation of the amounts and relative molar ratios of PEI and IL can be correlated to the nanorods AR as displayed in Fig. 3E. PEI and IL clearly have an adverse effect that allows the tuning of the nanorods morphology in our single-step protocol, beyond what has been reported by the variation of the CTAB or nitrate concentrations. ${ }^{38,39}$ In particular, the presence of PEI limits the growth along the $\{111\}$ facets. Indeed, a large excess of PEI results in the formation of isotropic nanoparticles only (Fig. S4, ESI $\dagger$ ). This suggests that the multiple cross-linked protonated amine moieties of PEI interfere with the CTAB-driven zipping mechanism. ${ }^{8}$ Conversely, the marked increase of the nanorod AR upon the addition of IL can be attributed to a catanionic effect in the CTAB SAM formation when associated with the $\mathrm{HexSO}_{4}$ anion that result in a more stable form of the gold/CTAB-IL interface. ${ }^{40}$

High aspect ratio $\mathrm{Au}$ nanoparticles exhibit specific optical properties which can be investigated in solution by UV-visible spectrophotometry. ${ }^{19,41}$ Fig. 4 presents the absorption spectra of the starting PEI-capped seeds and the colloidal suspensions obtained in conditions A, B, C and D. The four spectra of nanorod samples share a double feature which is a sharp peak at $280 \mathrm{~nm}$ and a broad peak between 500 and $800 \mathrm{~nm}$. The UV peak is associated with the presence of the IL, while PEI contributes at higher UV energies. The broad composite band in the visible is attributed to the superposition of the nanorod transverse and longitudinal surface plasmon (SP) modes. The transverse mode contributes to the onset at $500 \mathrm{~nm}$. The samples are predominantly composed of crystalline nanorods, the length of which is not strictly uniform thus resulting in a continuous series of higher order longitudinal modes in the $600-800 \mathrm{~nm}$ range as demonstrated experimentally $^{42}$ and theoretically ${ }^{42,43}$ (see also Fig. S2, ESI + ). In particular, the spectra show an increased intensity in the lower energy as the PEI : IL molar ratio increases from growth media A to D in agreement with the microscopic observations. The overlap of many high order SP modes results in a broad feature, the high energy edge of which is set by the transverse mode that remains unchanged since the particle diameter or thickness is in the $40-80 \mathrm{~nm}$ range. Meanwhile, the low energy edge shifts towards near-infrared as the nanorods grow longer. Other morphologies such as platelets also contribute to the $600-800$ nm absorbance feature.

The non-specific adsorption of PEI on all crystalline facets reduces the differential growth speed initially set by the selective adsorption of CTAB onto the $\{100\}$ facets. Conversely, increasing the amount of IL produces a high yield of micrometer-long Au NR with monodisperse diameter. While this effect is moderate in the presence of $615 \mu \mathrm{M}$ PEI (conditions A and B in Fig. 3), it is readily effective when the PEI concentration is reduced by a factor of 5000 (conditions C and D in Fig. 3). Yet the effect of the IL on the nanorods nucleation and growth cannot be identified from the morphological analysis and, hence, was specifically examined by a combined approach using Dynamic Light Scattering (DLS) and Atomic Force Microscopy (AFM).

The evolution of the hydrodynamic diameter of PEI-capped $\mathrm{Au}$ seeds in the CTAB-rich growth medium in the presence of added

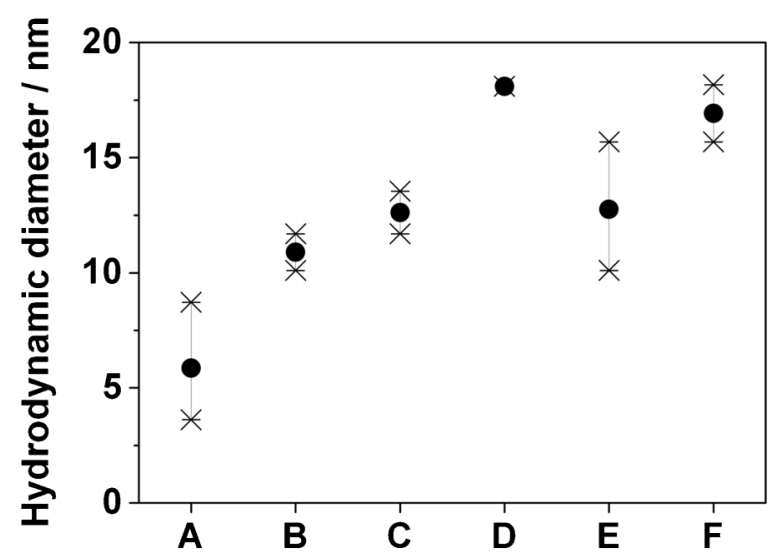

Fig. 5 Comparison of the DLS apparent diameters of $(A, B)$ the CTAB micelles formed in the model growth medium (A) before and (B) after addition of extra IL without Au seeds; of (C, D) diluted Au seeds (C) without or (D) with extra IL added and of $(E, F)$ concentrated Au seeds (E) without or (F) with extra IL added. 
emimHexSO $\mathrm{IL}_{4} \mathrm{IL}$ is monitored by DLS and reported in Fig. 5 . The growth medium of conditions A (resp. B) in Fig. 3 is modelled by an aqueous solution of $10 \mathrm{mM} \mathrm{CTAB}, 4.1 \mathrm{mM}$ (resp. $8.2 \mathrm{mM}$ ) IL and $0.38 \mathrm{mM}$ PEI to which the Au seeds are added. The DLS spectra of this reference medium show the presence of a single distribution of $6 \mathrm{~nm}$ diameter CTAB micelles (Fig. 5A). The spread of the apparent diameter is quite large (standard deviation, $\sigma$, is $2.5 \mathrm{~nm}$ ) indicating an inhomogeneous and fluctuating distribution of micelle sizes ascribed to the destructuring action of PEI. However, upon addition of extra IL up to a final concentration of $8.2 \mathrm{mM}$, the single distribution shifts to an apparent diameter of $11 \mathrm{~nm}$ with a marked reduction of the data spread $(\sigma=1 \mathrm{~nm}$, Fig. 5B). This suggests that the IL counteracts the entropic effect of PEI and interacts significantly with CTAB layers, most likely by van der Waals interaction between the cetyl and hexyl chains and the catanionic interactions of the ammonium, sulfate and emim ionic species. $^{44}$ This interaction results in the formation of very monodisperse CTAB/IL colloidal objects of larger size than pure CTAB micelles. When the pure $\mathrm{IL}$ is replaced by an aliquot of $\mathrm{Au}$ seeds in IL (Fig. 5C), very similar single-peaked DLS spectra are obtained with a narrow data dispersion $(\sigma=1 \mathrm{~nm})$ but centered on an average value of $13 \mathrm{~nm}$. This suggests that the sub-5 nm Au seeds could be encapsulated in the organized CTAB/IL spherical colloid. Interestingly, when extra IL is added to mimic the growth media B or D, the average diameter increases even more to $18 \pm$ $0.5 \mathrm{~nm}$ (Fig. 5D). The diameter increase by $5 \mathrm{~nm}$ and a reduction of the polydispersity from $\sigma=3 \mathrm{~nm}$ to $\sigma=1.5 \mathrm{~nm}$ is also observed for a twenty-fold increase of the seed concentration (Fig. 5E-F).

This DLS study is supported by AFM height measurements of PEI-capped Au seeds deposited onto glass substrates. An increase in apparent height from 4 to $7 \mathrm{~nm}$ is measured upon exposure to an IL drop (Fig. S7-S8, ESI†). Moreover, the dewetting of the drop leaves the Au seeds with a larger apparent height $(5.5 \mathrm{~nm})$ and with a systematic and non-evaporating liquid corona attributed to IL trapped in the PEI shell. The interactions of the emimHexSO $\mathrm{IL}_{4}$ with the $\mathrm{CTAB}$ and the immediate surroundings of the $\mathrm{Au}$ nanoparticles appear clearly in these DLS and AFM experiments and generally contribute to an improved organization of the surfactant phase. This provides further insight on the role of the IL during the nanorod growth. At the nucleation stage, when the seeds are capped with PEI, the facet-specific morphosynthetic action of CTAB is hindered by the non-specific adsorption of the multiple amine groups that equally inhibits the growth of all facets. Moreover, the cationic branched PEI shell also constitutes an electrostatic diffusion barrier to the $\mathrm{Au}(\mathrm{I}) / \mathrm{CTAB}$ precursor species. As in the case of low $\mathrm{HAuCl}_{4}$ conditions, ${ }^{45}$ this effective local depletion in $\mathrm{Au}(\mathrm{I})$ near the $\mathrm{Au}$ surface limits the facet discrimination during the growth. On the contrary, when the IL is added to the CTAB solution, with or without Au seeds, it results in an increase of both size and monodispersity of the suspended colloidal objects. It also coincides with the formation of nanorods with larger AR. The affinity of the IL for both the PEI shell and the CTAB suggests that the IL has a screening effect on the charged PEI and facilitates the permeation of the Au(I)/CTAB complex through the PEI shell. Moreover, the IL/CTAB interaction improves the cohesion of the CTAB layer and allow a better adsorption to the $\{100\}$ side facets. Overall, the addition of IL restores a higher local concentration of precursor and the kinetically-favored discrimination of the $\{100\}$ and $\{111\}$ facet growth, which results in longer $\mathrm{Au} \mathrm{NR}$.

In conclusion, new PEI-capped $\mathrm{Au}$ nanoparticles have been synthesized in emimHexSO $\mathrm{IL}_{4}$ and were used as seeds in a modified protocol of the conventional one-step $\mathrm{Au}$ NR synthesis. In particular, the addition of PEI and emimHexSO $\mathrm{IL}_{4}$ was shown to alter the nanocrystal growth. The length and $\mathrm{AR}$ of the nanorods was tuned by varying the IL : PEI molar ratio. A separate DLS/AFM study suggests that the non-specific adsorption of the PEI shell on all $\mathrm{Au}$ facets limits the final anisotropy of the particles. Conversely, the IL/CTAB interaction reinforces the organization of the surfactant and restores its facet-specific growth inhibition action that accounts for the formation of high $\mathrm{AR}$ nanorods.

The joint incorporation of PEI and IL in the nanorods organic shell opens the possibility to proceed more easily to the postfunctionalization of the $\mathrm{Au}$ surface, which has been a major drawback of the efficient morphosynthetic action of CTAB and which could have broad implications in biological applications of metal nanoparticles. For example, the cellular uptake of nanorods has been used to transfect drugs, RNA, proteins and plasmids, which could be promoted by PEI, a known transfecting agent. ${ }^{46-52}$ Similarly, bioimaging, immunoassays and light-triggered drug delivery ${ }^{52}$ can only be performed, in vivo, by enabling the cellular uptake or adhesion and by tuning the nanorods AR so that their absorption is maximized in the transparency window of biological tissues, which lies in the near-infrared range. ${ }^{50}$

This work was funded in part by the EU ERC (Starting Grant No. 203872-COMOSYEL), the French ANR (Grant No. ANR-09BLAN-0049-01-Plastips), the National University of Costa Rica, the National Science Bureau of Costa Rica (MICIT, CONICIT) and the German DAAD. The authors thank C. Severac (ITAV-CNRS UMS 3039) for assistance in liquid AFM experiments and A. Teulle and C. Girard for performing GDM calculations.

\section{References}

1 M. De, P. S. Ghosh and V. M. Rotello, Adv. Mater., 2008, 20, 4225-4241.

2 C. J. Murphy, A. M. Gole, J. W. Stone, P. N. Sisco, A. M. Alkilany, E. C. Goldsmith and S. C. Baxter, Acc. Chem. Res., 2008, 41, 1721-1730.

3 D. Astruc, F. Lu and J. R. Aranzaes, Angew. Chem., Int. Ed., 2005, 44, 7852-7872.

4 C. Girard and E. Dujardin, J. Opt. A: Pure Appl. Opt., 2006, 8, S73-S86.

5 N. R. Jana, L. Gearheart and C. J. Murphy, Adv. Mater., 2001, 13, 1389-1393.

6 C. J. Johnson, E. Dujardin, S. A. Davis, C. J. Murphy and S. Mann, J. Mater. Chem., 2002, 12, 1765-1770.

7 C. J. Murphy and N. R. Jana, Adv. Mater., 2002, 14, 80-82.

8 J. Gao, C. M. Bender and C. J. Murphy, Langmuir, 2003, 19, 9065-9070.

9 Y. G. Sun, B. Gates, B. Mayers and Y. N. Xia, Nano Lett., 2002, 2, 165-168. 
10 F. Kim, K. Sohn, J. Wu and J. Huang, J. Am. Chem. Soc., 2008, 130, 14442-14443.

11 N. R. Jana, L. Gearheart and C. J. Murphy, J. Phys. Chem. B, 2001, 105, 4065-4067.

12 H. C. Chu, C. H. Kuo and M. H. Huang, Inorg. Chem., 2006, 45, 808-813.

13 I. Pastoriza-Santos and L. M. Liz-Marzan, J. Mater. Chem., 2008, 18, 1724-1737.

14 L. Kemal, X. C. Jiang, K. Wong and A. B. Yu, J. Phys. Chem. C, 2008, 112, 15656-15664.

15 R. M. Dickson and L. A. Lyon, J. Phys. Chem. B, 2000, 104, 6095-6098.

16 H. Ditlbacher, A. Hohenau, D. Wagner, U. Kreibig, M. Rogers, F. Hofer, F. R. Aussenegg and J. R. Krenn, Phys. Rev. Lett., 2005, 95.

17 M. Song, A. Thete, J. Berthelot, Q. Fu, D. Zhang, G. C. des Francs, E. Dujardin and A. Bouhelier, Nanotechnology, 2013, 24.

18 L. F. Gou and C. J. Murphy, Chem. Mater., 2005, 17, 3668-3672.

19 J. Sharma, B. A. Kakade, N. K. Chaki, S. Mahima and V. K. Pillai, J. Nanosci. Nanotechnol., 2007, 7, 2139-2150.

20 C. J. Murphy, T. K. San, A. M. Gole, C. J. Orendorff, J. X. Gao, L. Gou, S. E. Hunyadi and T. Li, J. Phys. Chem. B, 2005, 109, 13857-13870.

21 B. Nikoobakht and M. A. El-Sayed, Langmuir, 2001, 17, 6368-6374.

22 Y. J. Xiong, I. Washio, J. Y. Chen, H. G. Cai, Z. Y. Li and Y. N. Xia, Langmuir, 2006, 22, 8563-8570.

23 M. Tsuji, M. Hashimoto, Y. Nishizawa and T. Tsuji, Mater. Lett., 2004, 58, 2326-2330.

24 D. Zhang, T. Yan, H. Li and L. Shi, Microporous Mesoporous Mater., 2011, 141, 110-118.

25 H. J. Ryu, L. Sanchez, H. A. Keul, A. Raj and M. R. Bockstaller, Angew. Chem., Int. Ed., 2008, 47, 7639-7643.

26 T. Y. Kim, W. J. Kim, S. H. Hong, J. E. Kim and K. S. Suh, Angew. Chem., Int. Ed., 2009, 48, 3806-3809.

27 H. Itoh, K. Naka and Y. Chujo, J. Am. Chem. Soc., 2004, 126, 3026-3027.

28 Y. Zhou, Curr. Nanosci., 2005, 1, 35-42.

29 Z. Ma, J. H. Yu and S. Dai, Adv. Mater., 2010, 22, 261-285.

30 Z. H. Li, Z. M. Liu, J. L. Zhang, B. X. Han, J. M. Du, Y. N. Gao and T. Jiang, J. Phys. Chem. B, 2005, 109, 14445-14448.

31 J. M. Zhu, Y. H. Shen, A. J. Xie, L. G. Qiu, Q. Zhang and S. Y. Zhang, J. Phys. Chem. C, 2007, 111, 7629-7633.

32 J. Dupont and J. D. Scholten, Chem. Soc. Rev., 2010, 39, 1780-1804.
33 R. Talhout and B. F. N. Engberts, Langmuir, 1997, 13, 5001-5006.

34 K. K. Caswell, J. N. Wilson, U. H. F. Bunz and C. J. Murphy, J. Am. Chem. Soc., 2003, 125, 13914-13915.

35 K. G. Thomas, S. Barazzouk, B. I. Ipe, S. T. S. Joseph and P. V. Kamat, J. Phys. Chem. B, 2004, 108, 13066-13068.

36 T. Niidome, M. Yamagata, Y. Okamoto, Y. Akiyama, H. Takahashi, T. Kawano, Y. Katayama and Y. Niidome, J. Controlled Release, 2006, 114, 343-347.

37 S. Frasca, O. Rojas, J. Salewski, B. Neumann, K. Stiba, I. M. Weidinger, B. Tiersch, S. Leimkühler, J. Koetz and U. Wollenberger, Bioelectrochemistry, 2012, 87, 33-41.

38 H. Y. Wu, H. C. Chu, T. J. Kuo, C. L. Kuo and M. H. Huang, Chem. Mater., 2005, 17, 6447-6451.

39 H. Y. Wu, W. L. Huang and M. H. Huang, Cryst. Growth Des., 2007, 7, 831-835.

40 P. Andreozzi, S. S. Funari, C. La Mesa, P. Mariani, M. G. Ortore, R. Sinibaldi and F. Spinozzi, J. Phys. Chem. B, 2010, 114, 8056-8060.

41 M. A. El-Sayed, Acc. Chem. Res., 2001, 34, 257-264.

42 S. Eustis and M. A. El-Sayed, J. Appl. Phys., 2006, 100.

43 A. L. Schmucker, N. Harris, M. J. Banholzer, M. G. Blaber, K. D. Osberg, G. C. Schatz and C. A. Mirkin, ACS Nano, 2010, 4, 5453-5463.

44 S. R. Raghavan, G. Fritz and E. W. Kaler, Langmuir, 2002, 18, 3797-3803.

45 N. R. Jana, L. Gearheart and C. J. Murphy, Chem. Mater., 2001, 13, 2313-2322.

46 B. D. Chithrani and W. C. W. Chan, Nano Lett., 2007, 7, 1542-1550.

47 A. C. Bonoiu, S. D. Mahajan, H. Ding, I. Roy, K.-T. Yong, R. Kumar, R. Hu, E. J. Bergey, S. A. Schwartz and P. N. Prasad, Proc. Natl. Acad. Sci. U. S. A., 2009, 106, 5546-5550.

48 A. K. Salem, P. C. Searson and K. W. Leong, Nat. Mater., 2003, 2, 668-671.

49 L. Xu, Y. Liu, Z. Chen, W. Li, Y. Liu, L. Wang, Y. Liu, X. Wu, Y. Ji, Y. Zhao, L. Ma, Y. Shao and C. Chen, Nano Lett., 2012, 12, 2003-2012.

50 X. H. Huang, I. H. El-Sayed, W. Qian and M. A. El-Sayed, J. Am. Chem. Soc., 2006, 128, 2115-2120.

51 K. M. Mayer, S. Lee, H. Liao, B. C. Rostro, A. Fuentes, P. T. Scully, C. L. Nehl and J. H. Hafner, ACS Nano, 2008, 2, 687-692.

52 H. Takahashi, Y. Niidome and S. Yamada, Chem. Commun., 2005, 2247-2249. 